\title{
The Impact of Water Circulation on the Year-class Abundance Dynamics of Redfish and Cod on the Flemish Cap
}

\author{
Borovkov V.A., Vaskov A.A. and A. L. Karsakov \\ Polar Research Institute of Marine Fisheries and Oceanography (PINRO), \\ 6 Knipovich St., 183763 Murmansk, Russia
}

Borovkov, V.A., A.A. Vaskov, and A.L. Karsakov. 2006. The Impact of Water Circulation on the Year-class Abundance Dynamics of Redfish and Cod on the Flemish Cap. J. Northw. Atl. Fish. Sci., 37: 127-134. doi:10.2960/J.v37.m553

\begin{abstract}
This paper studies the formation of abundance of redfish (Sebastes spp) and cod (Gadus morhua) year-classes under varying conditions of spawning, of which a key role is played by water circulation. A statistically significant relationship $(r=0.601, p=0.002)$ between survival of cod year-classes and atmospheric cyclonic activity was revealed. This relationship is based on the effect of storms on water circulation over the Flemish Cap and supports the hypothesis on the impact of year-to-year variation in the Taylor column circulation on the cod survival.By contrast with cod, the survival of larval redfish is to a large extent related to the position of the North Atlantic Current, which impacts on the main spawning grounds (southern slopes of the bank) and correspondingly may influence the drift of larvae away from the bank. This is supported by a reciprocal relationship $(r=-0.565, p=0.012)$ between redfish survival rate on the Flemish Cap and position of the northern front of the Gulf Stream by latitude south of the Grand Banks near $51^{\circ} \mathrm{W}$.The emergence of very strong year-classes of redfish in Div. $3 \mathrm{M}$ is likely to be related more to the hydrographic conditions rather than to the status of the spawning stock. It is most probable that a stronger anticyclonic eddy leds to increased year-class strength, while weak eddies result in a more powerful drift of larval and juvenile redfish away from the bank. In turn, the emergence of strong year-classes may, in a way, be an "indicator" of specific types of water circulation on the bank.
\end{abstract}

Keywords: cod, currents, Flemish Cap, hydrography, larvae, redfish, retention.

\section{Introduction}

In the Northwest Atlantic, hydrographic conditions have a significant impact on biological production, abundance of fish, their distribution, behaviour and other characteristics, the knowledge of which is vital for sustainable management of fisheries. One of the important hydrographic parameters, particularly during the early life history of organisms, is water circulation. Hydrographic regime on the Flemish Cap is conditioned by the Flemish Cap branch of the Labrador Current, which creates a Taylor column: an almost permanent anticyclonic eddy over its shallowest part. Due to convergence of waters to the cycle axis, an anticyclonic ring of currents creates bounds for the distribution of ichthyoplankton, within which juvenile fish, cod and redfish in the first place, are retained when settling to the near-bottom of shallow waters. As the bank, which is surrounded by deep oceanic waters, is relatively small, this factor is important for the successful reproduction of fish. It was shown that the Flemish Cap cod ichthyoplankton survival depended on the dynamic condition of waters over the bank and grew with the anticyclonic eddy to become stronger (Borovkov et al., 1978).

This paper gives analysis of the impact of water circulation on the Flemish Cap on the dynamics of cod and redfish stocks on the Flemish Cap, which are considered independent populations from other areas.

\section{Material and Methods}

The paper uses oceanographic data collected during Russian surveys on the Flemish Cap in 1978-1993. A survival index $(\ln (R / S S B))$ was used as the main 
biological parameter for cod (Gadus morhua) and redfish (Sebastes spp). For cod, it was estimated as a ratio of yearling abundance $(R)$ to spawning biomass $(S S B)$ of the parent stock using VPA results for 19731997 (Vázquez and Motos, MS 1999). For redfish, survival index was estimated with a similar method using Canadian (1979-1985) and EU (1988-2002) survey data (Avila de Melo et al., MS 2003), using the calculated $R$ abundance of individuals of $\leq 5 \mathrm{~cm}$ in length.

Hydrometeorological information on the mean monthly sea level pressure over the Flemish Cap area $\left(45^{\circ}-50^{\circ} \mathrm{N}, 49^{\circ}-41^{\circ} \mathrm{W}\right)$ for the period from 1970 to 2003 was taken from the NOAA Operational Model Archive Distribution System (http://nomad2.ncep.noaa.gov/) and Department of Fisheries and Oceans of Canada (DFO) within the AZMP Programme (http:/www.meds-sdmm. dfo-mpo.gc.ca/zmp/main_zmp_e.html) on the mean monthly position of the Gulf Stream front at $51^{\circ} \mathrm{W}$ for the period from 1979 to 2001 .

Oceanographic data from Russian surveys on the Flemish Cap in 1978-1993 were analyzed by using the dynamic method (Zubov and Mamaev, 1956) and maps of surface water geostrophic circulation were drawn. The depth of 200 dbar was taken as zero surface.

\section{Results and Discussion}

Results from Russian surveys on the Flemish Cap have shown that the dynamics of redfish abundance is indicative of a considerable variation in the strength of year-classes (Vaskov, 2002). Such variation in the emergence of weak and strong year-classes was noted earlier for the Flemish Cap cod (Konstantinov and Noskov, MS 1977).

Between 1971 and 2001, strong year-classes of redfish in Div. 3M were noted in 1969-1970, 1972-1973, 1979-1980, 1985-1986, 1989-1990 and 1999-2000. The analysis showed that in the 1970s, strong year-classes emerged every 2-4 years. Later, this time interval increased and the last strong year-class emerged 9-10 years after the previous one. It should be noted, that the yearclass of 1969-1970, which was quite abundant in 1971, was later found only in surveys undertaken in 1974-1975 (Fig. 1).

According to Canadian survey data for 1979-1985 (Avila de Melo et al., MS 2003) the spawning stock of redfish on the Flemish Cap varied from 57700 to $111700 \mathrm{t}$ (metric tons) (Fig. 2). The proportion of the spawning stock in the total stock remained practically unchanged,
$42 \%$ on average, while strong year-classes were noted to emerge only in 1979-1980 and 1985-1986.

EU surveys of 1988-2002 showed a decline of both the total stock and the spawning stock (Avila de Melo et al., MS 2003). The proportion of the spawning stock in 1988-1991 varied from 22 to $28 \%$. However, in 19891990 a strong year-class emerged which dominated the age structure of the whole stock until 1999. The next strong year-class was found on the Flemish Cap in 19992000 , when the spawning stock was estimated at $10-17 \%$ and the total one was at a very low level (Fig. 2).

Overall, the circulation of waters on the Flemish Cap includes the following elements. The Flemish Cap branch of the Labrador Current of relatively low temperature and salinity flows over the northern and partly eastern slopes of the bank (Elizarov and Prokhorov, 1958; Buzdalin and Elizarov, 1962). On the southern slopes of the bank these waters meet with warmer and more saline waters brought by the North-Atlantic Current. The North-Atlantic Current carries most of the waters of the Flemish Cap Current eastward and northeastward. There is an anticyclonic eddy in the shallow central part of the bank, which is in direct contact with the Flemish Cap Current.

The mentioned above circulation elements are presented in the majority of the sea surface dynamic topography maps made using data from hydrographic researches conducted by PINRO in that area. Later studies (Kudlo et al., 1984) reaffirmed the existence of an almost permanent anticyclonic eddy on the bank. However, in addition to this pattern of circulation, there may be other patterns of water movement seen there in some years. These patterns were categorized into four types. The first two are the most common types (an extensive anticyclonic eddy with one centre and an extensive anticyclonic eddy with a number of local centres), according to circulation pattern they are not differing much and in fact could be classified as sub-types of one and the same type (frequency about $70 \%$ ). The third type of circulation is peculiar for having a transit transport of water, in other words, for the absence of closed water cycle in the central part of the bank. This type of water circulation on the bank is most rare of the types considered (frequency about 7\%). Under the fourth type of circulation there exist both local eddies and a transit flow across the bank, i.e. the water circulation is of mixed pattern (frequency about $25 \%$ ).

Figure 3 shows an example of maps of surface water geostrophic circulation on the Flemish Cap drawn with 

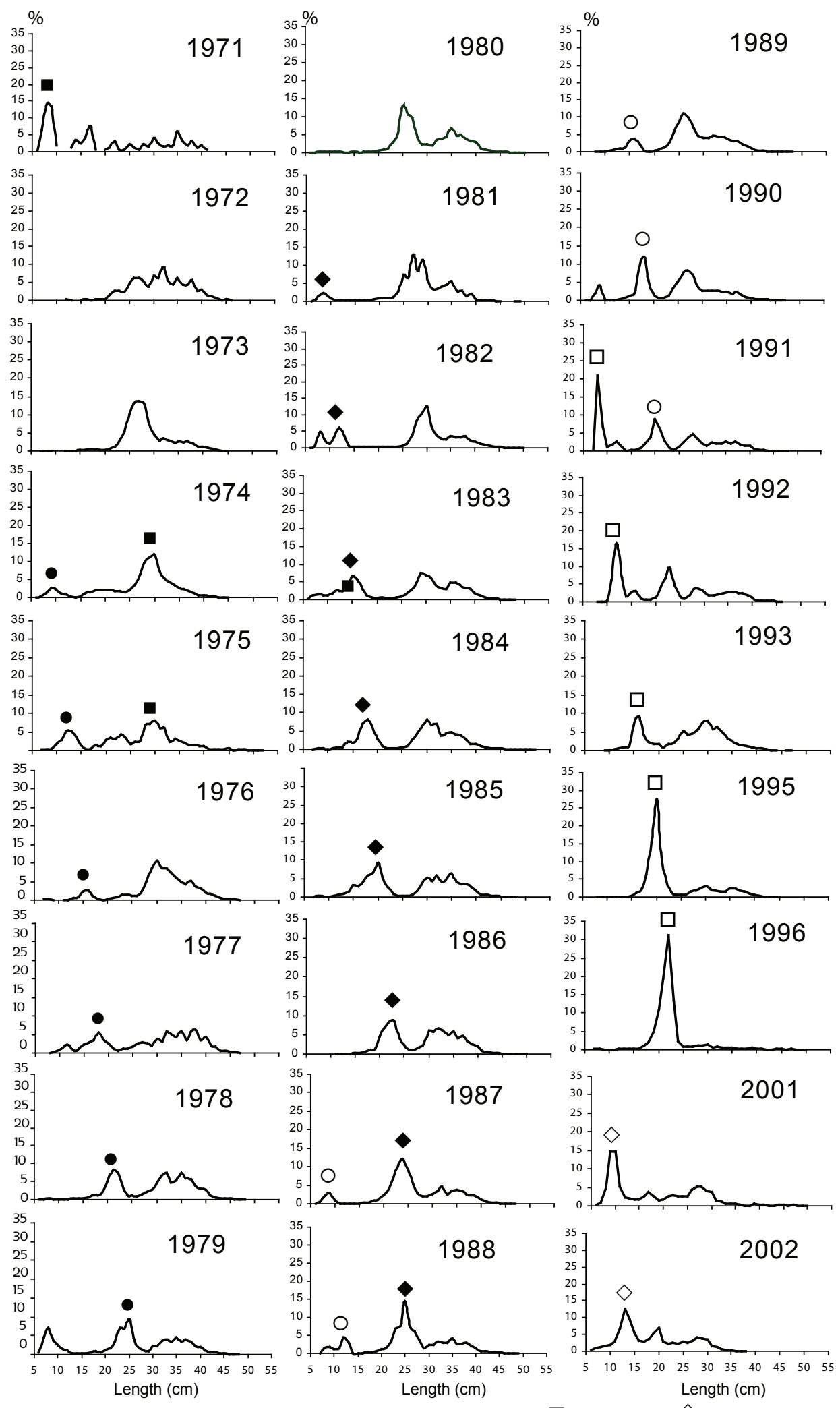

1969-1970
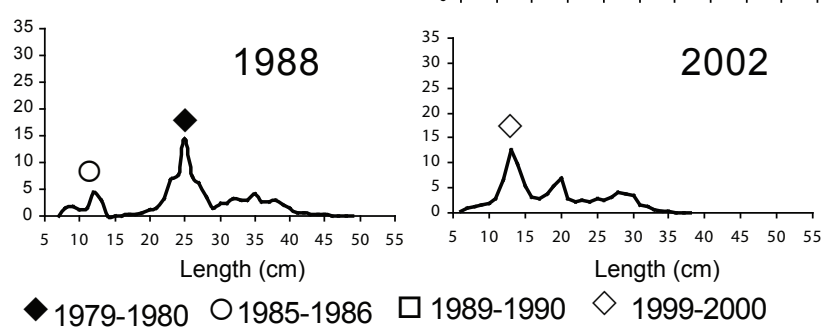

Fig. 1. Length composition of redfish in Div. 3M based on data from Russian surveys in 1971-2002 Strong year-classes in the diagrams are shown by symbol. 


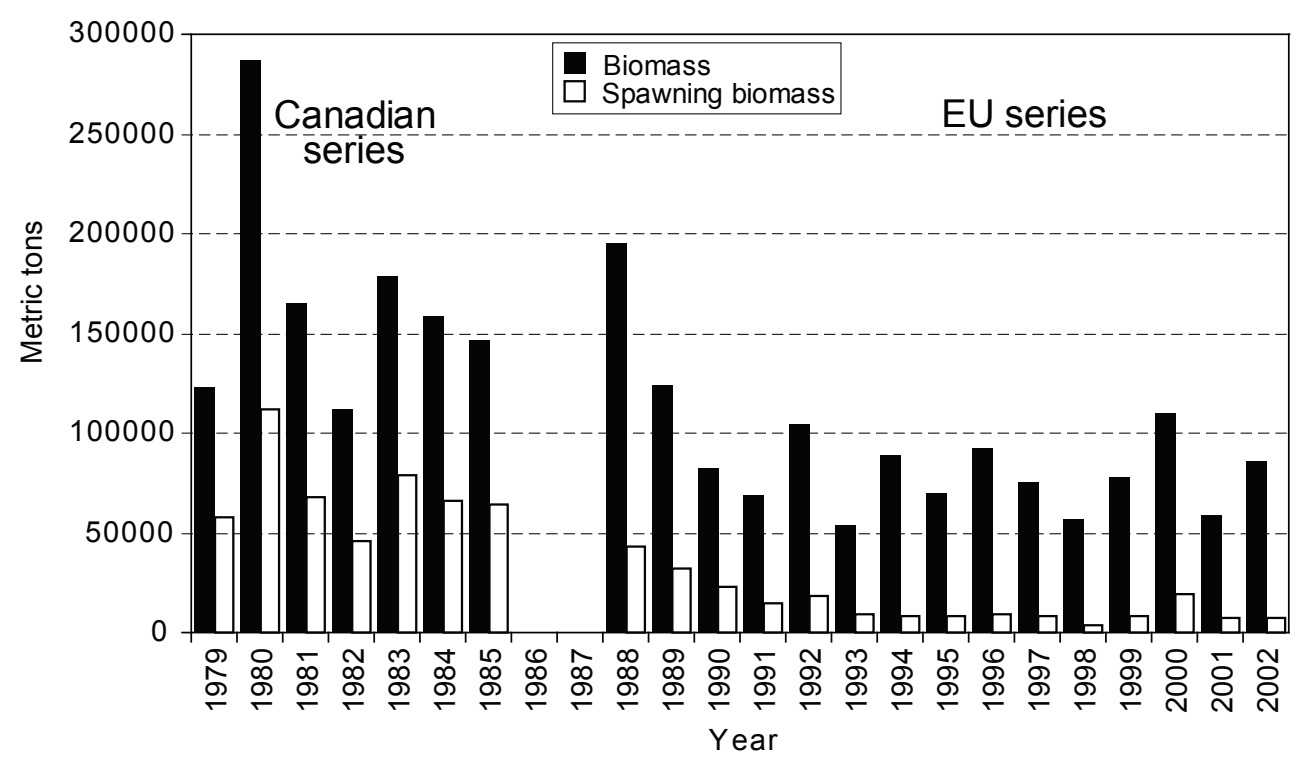

Fig. 2. Total biomass and spawning biomass (metric tons) of redfish in Div. 3M from Canadian (1979-1985) and EU (1988-2002) bottom trawl surveys.

data from Russian surveys in 1988-1993. All maps clearly show a closed anticyclonic water cycle of irregular geometric shape in the central part of the bank. Comparing different years one can easily identify differences in the size and configuration of areas delineated by closed isolines, as well as varying number and density of these isohypses, which is indicative of continuous evolution of the water cycle. Most of the cases considered can be referred to the most common first two types of circulation, except for 1990, when the anticyclonic water cycle on the bank did not have a closed contour and it, therefore, could probably be categorized into type four.

Regrettably, for observations in that area undertaken irregularly over the past 20 years, it was not possible to establish a year-to-year and season-to-season variation pattern for the water cycle. However, there are grounds to believe that among the reasons behind variation of water circulation types on the bank an important role is played by cyclonic activity on the Flemish Cap (Kudlo et al., 1984). In the periods of weakened cyclonic activity, which are characterized by the absence of storms, the circulation of water on the bank has predominantly a form of anticyclonic eddy (the first two types of circulation). By contrast, after strong cyclones passed the bank (Fig. 4), and in the following period of about 1-2 weeks meandering flows typical of circulation type three and four are noted in shallow waters on the bank.

Viewing the occurrence of atmospheric cyclones over the bank as a sporadic event it could be assumed that in the long-term mean aspect the probability of disruption of anticyclonic water circulation increases in the autumn and winter (Fig. 5), i.e. in the period of more active cyclonic activity in the atmosphere, and declines in summer, when cyclogenesis becomes weaker (Kudlo and Borovkov, 1981). The existence of these intra-annual variations of anticyclonic water circulation combined with specific features of biology of living marine organisms explains the presence of populations of bottom fish on the Flemish Cap - cod and redfish, and the absence of local capelin population. The existence of cod and redfish populations is attributed to that in the period between spawning and settling of juveniles down to deeper waters or seabed, which falls on the time from the end of last winter to the beginning of the next winter, a relative retention of pelagic eggs, larvae and fry of cod and redfish on the bank is achieved. Since the retention of passive migrants is dependent on how the anticyclonic eddy functions, which in the period noted above acts as a hydrodynamic trap, it becomes clear that it exists permanently on the bank or disappears for short periods of time only. Hence, the conditions of survival and living are relatively favourable for bottom species, which only develop in the pelagic zone in spring and summer, and unfavourable for capelin, the juvenile survival of which depends on the conditions of water circulation in the pelagic zone throughout the first year of life.

The hypothesis on the reasons of the Flemish Cap cod year-class strength fluctuations was based on the almost permanent character of the bank current system 

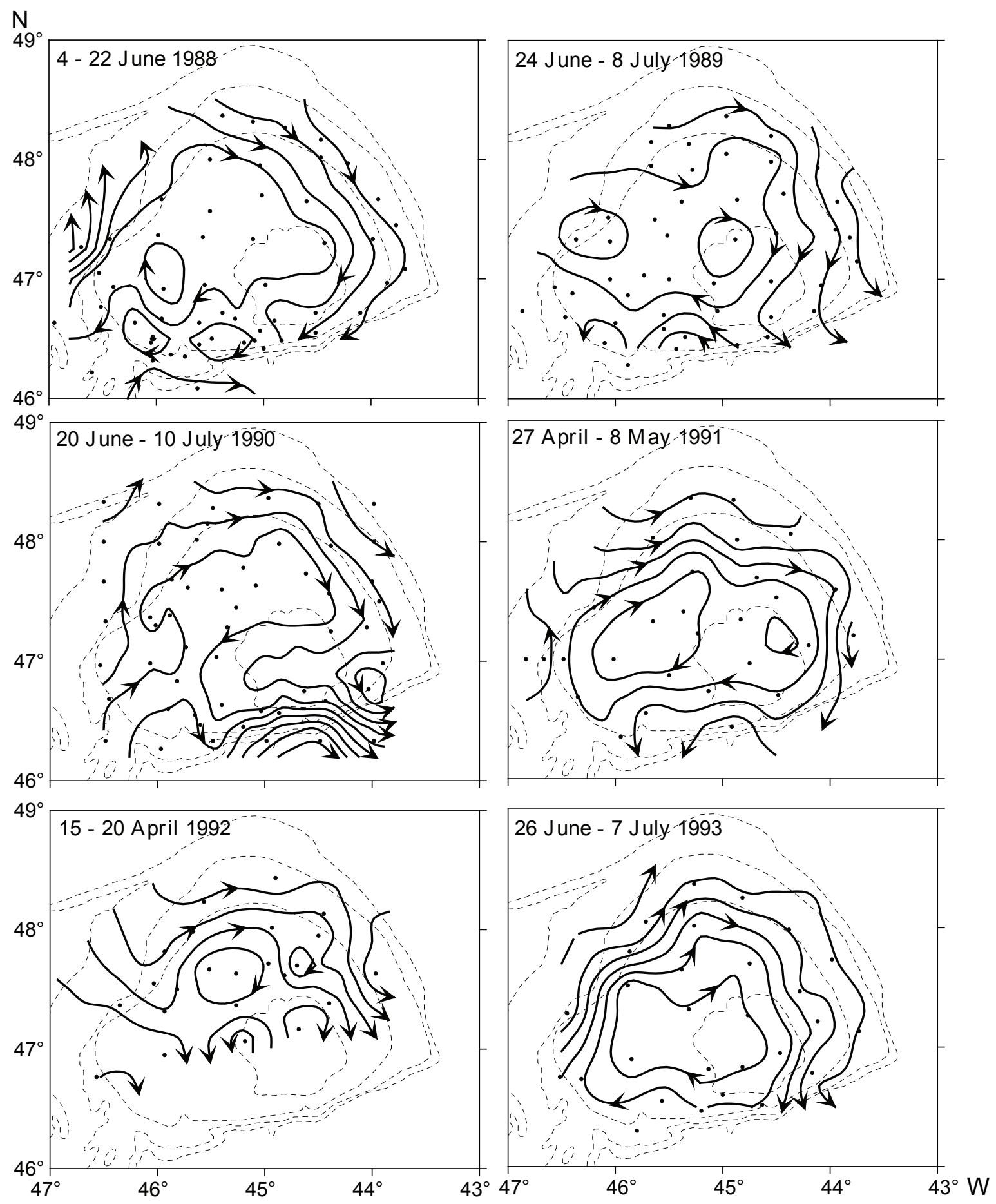

Fig. 3 Maps of geostrophic circulation of surface water on Flemish Cap against 200 dbar level in 1988-1993.

(Borovkov et al., 1978). The mechanism of the impact of water circulation on the production of cod was assumed to be the following: changes in the circulation lead to changes in the water convergence in the central part of the bank, and these, in turn, determine the degree of re- tention of pelagic eggs, larvae and fry of fish as well as phytoplankton and zooplankton within the bank. Subject to accumulation of organisms and micro seaweeds in shallow waters, the availability of food for larvae varies between years so does the degree of retention of pelagic 


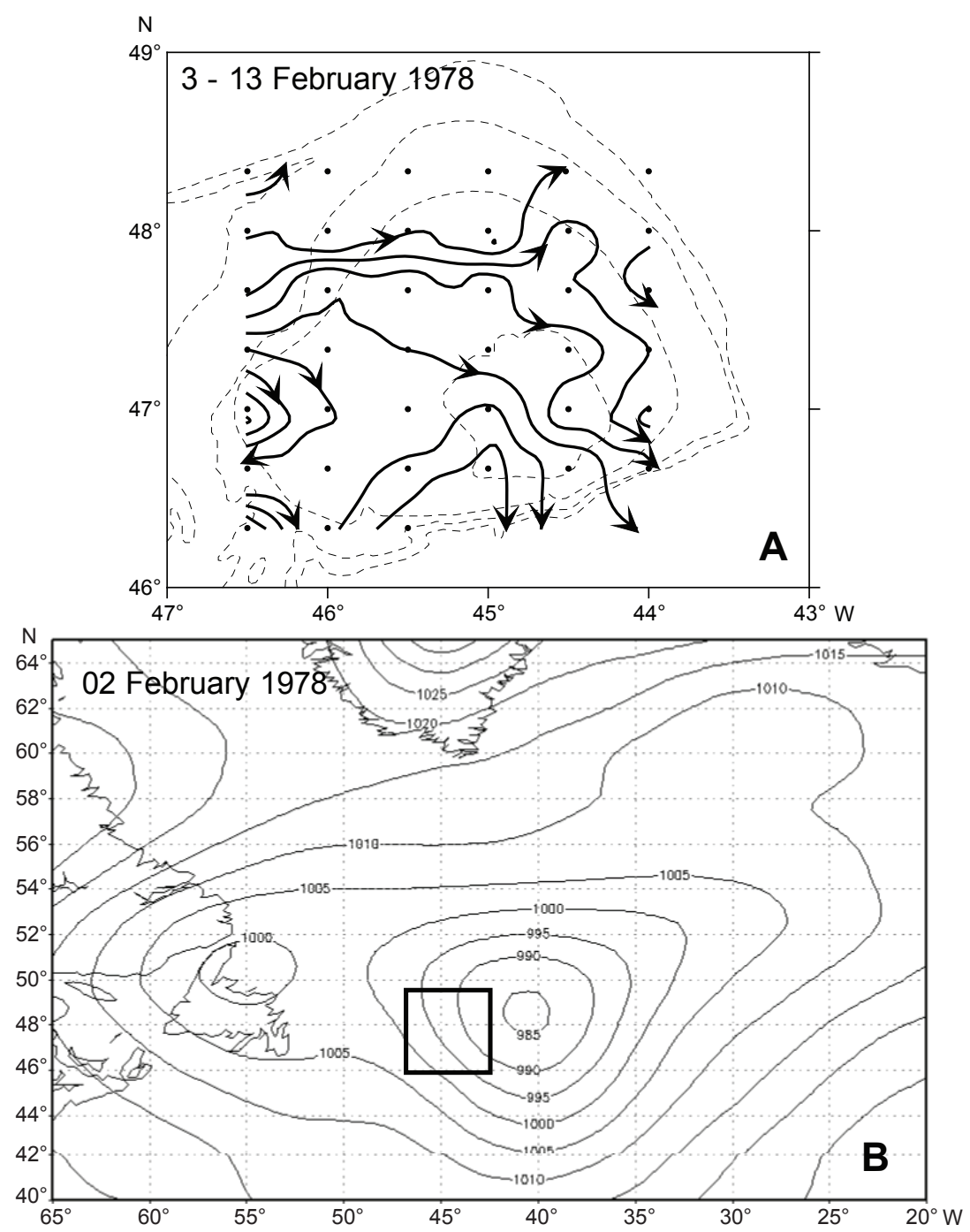

Fig. 4. Map of geostrophic circulation of surface water on Flemish Cap against $200 \mathrm{dbar}$ level in February 1978 (A) and distribution of the air pressure at 1000 mbar in the preceding period $(\mathbf{B})$. The Flemish Cap position on the map $(\mathbf{B})$ is shown by a square.

juveniles within the bank. The latter is the most important factor as it is exactly it, which regulates the year class strength.

Year-to-year variation in stability of anticyclonic eddy on the bank could be considered as a likely explanation of varying strength of year-classes of fish. Figure 6 shows variation of the mean sea level pressure in April-May over the bank $\left(45^{\circ} 50^{\prime} \mathrm{N}, 49^{\circ} 41^{\prime} \mathrm{W}\right)$ and survival indices $(\ln (R / S S B))$ of the Flemish Cap cod from 1973 to 1997 . The degree of correlation between these indices $(r=0.601, p=0.002)$ allows to conclude that with increasing mean monthly air pressure over the bank, i.e. with declining number of cyclones passing the bank, the survival rate of cod year-classes rises, and vice versa.

An important observation is the considerable differences in the strength of year-classes of cod and redfish. These are primarily explained by different biology and spawning grounds of the two species. As known, female redfish spawn larvae on the bank slopes at 400-600 m depth (Chekhova, 1972). In doing this they prefer the southern and south-western slopes of the Flemish Cap, i.e. areas under predominant impact of the North-Atlantic Current, whereas cod spawn closer to the central part of the bank and at shallower depth. Considering that the anticyclonic eddy is confined by size, the spawning areas 


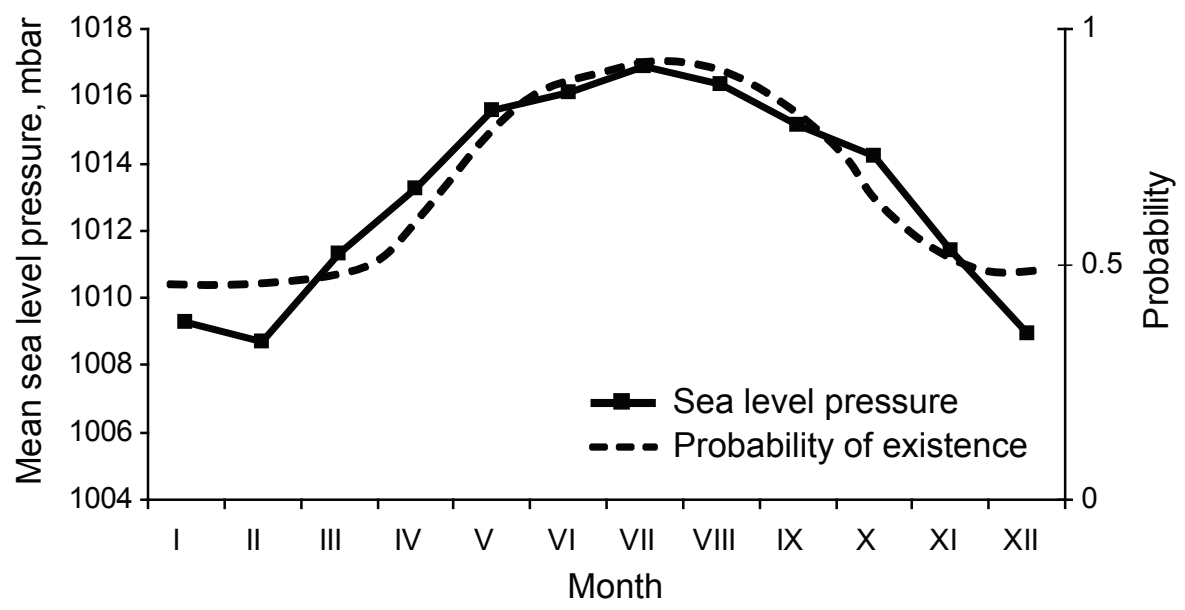

Fig. 5. Long-term mean seasonal variation of sea level pressure and hypothetical probability of existence of anticyclonic eddy on the Flemish Cap.

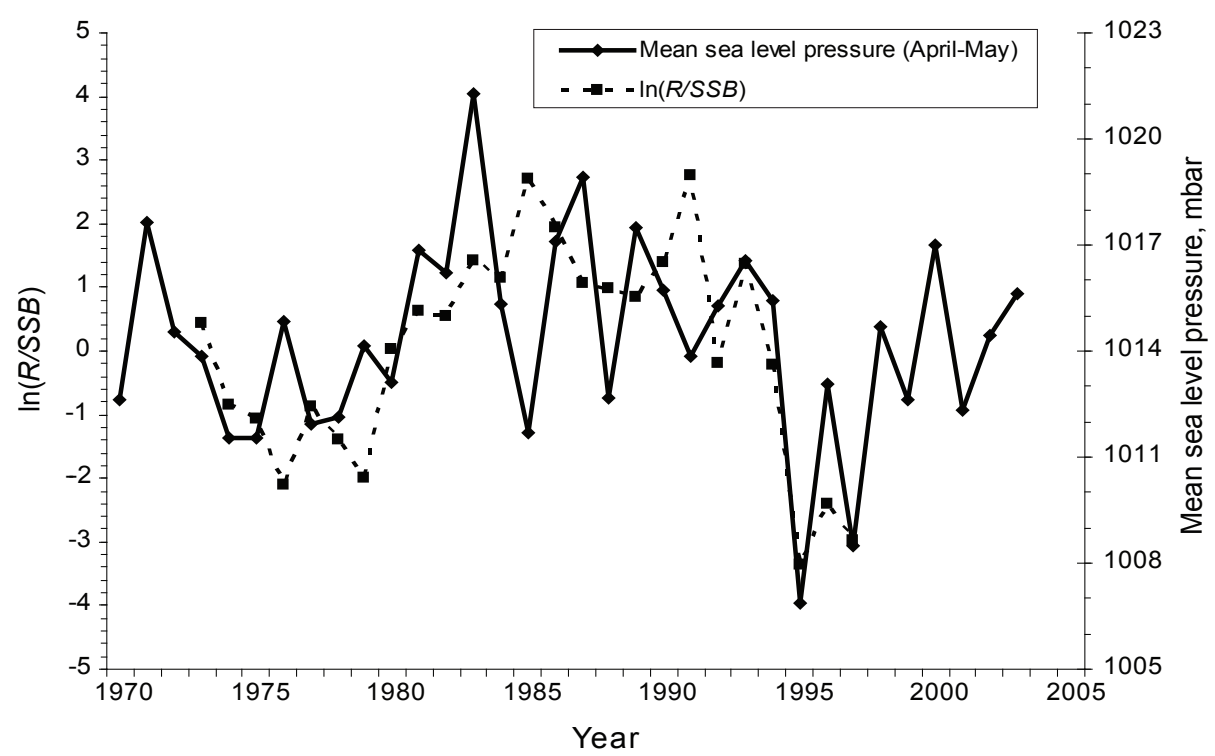

Fig. 6. Mean sea level pressure in April-May on the Flemish Cap $\left(45^{\circ}-50^{\circ} \mathrm{N}, 49^{\circ}-41^{\circ} \mathrm{W}\right)$ in 1970-2003 and survival index of the Flemish Cap cod in 1973-1997.

of redfish are probably not always within its coverage zone.

A comparison of redfish survival indices and variation in air pressure on the bank has shown no significant relationship. However, there exists a relationship between the survival of larval redfish on the Flemish Cap and water circulation in that area.

Figure 7 shows variations in the survival index $(\ln (R / S S B))$ of the Flemish Cap redfish and the position of northern front of the Gulf Stream by latitude south of the Grand Banks at $51^{\circ} \mathrm{W}$. There is a clear inverse relationship between them $(r=-0.565, p=0.012)$, which implies that the survival of redfish increases with a more southern position of the Gulf Stream relative to the tail of the Grand Banks, and vice versa. It can be suggested, that this effect results from a corresponding shift of the North Atlantic Current near the southern slopes of the Flemish Cap and its changed impact on the drift of larvae out of the bank.

In our view, the emergence of strong year-classes of redfish and cod in Div. $3 \mathrm{M}$ is, to a larger extent, re- 


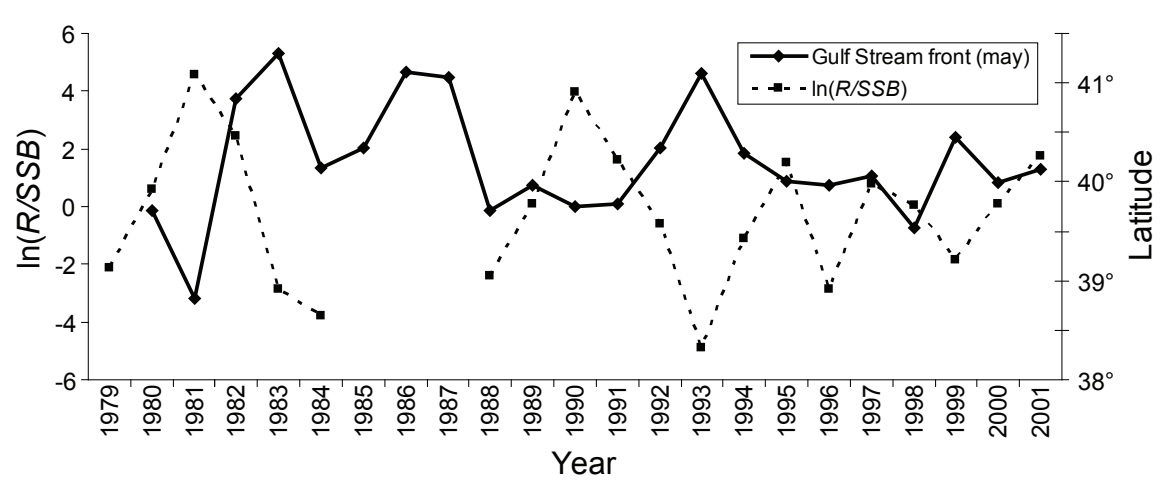

Fig. 7. Position of the northern front of the Gulf Stream by latitude near $51^{\circ} \mathrm{W}$ and survival index of redfish in 1979-2001.

lated to the hydrographic regime than to the status of the spawning stock. It is most likely, that stronger anticyclonic eddy on the bank gave rise to enhanced year class strength, while weakened one resulted in a more powerful drift of larval and juvenile redfish out of the bank. In addition, the position of the North Atlantic Current should be taken into consideration, which having an effect on the southern slopes of the Flemish Cap can also contribute to the drift of redfish larvae out of the bank. On the whole, studies undertaken are suggestive of the complexity of the mechanism of impact of water circulation on the Flemish Cap and of its important role in the reproduction of cod and redfish.

\section{References}

Avila de Melo, A.M., R. Alpoim and F. Saborido-Rey. MS 2003. An Assessment of Beaked Redfish (S. mentella and $S$. fasciatus) in NAFO Division 3M. NAFO SCR Doc. 03/45 Ser. No N4863, 73 p.

Borovkov V.A., V.D. Boitsov, and B.P. Kudlo. 1978. The role of water circulation in the formation of year class strength of the Flemish Cap cod. PINRO Collected Papers, edition XL, Murmansk, p. 133-139 (in Russian)

Buzdalin Yu.I. and A.A. Elizarov. 1962. Hydrographic conditions on the Newfoundland bank and near Labrador in 1960. In: Soviet fisheries research in the Northwest Atlantic. VNIRO-PINRO, Moscow, p. 155-171 (in Russian)
Chekhova V.A. 1972. Distribution of beaked redfish (Seabastes Mentella Travin) by depth on Flemish Cap. PINRO Collected Papers, edition XXVIII, Murmansk, pp. 199209 (in Russian)

Elizarov A.A. and V.S. Prokhorov. 1958. Hydrographic conditions and fisheries on Flemish Cap in March and May 1958. PINRO Science and Technical Bulletin, No. 3(7): 57-59 (in Russian)

Konstantinov, K.G., and A.S. Noskov. MS 1977. Report on the USSR investigations in the ICNAF area, 1976. ICNAF Sum. Doc. 77/VI/15, Serial No. N5071, 39 p.

Kudlo B.P. and V.A. Borovkov. 1981. Specific features of horizontal water circulation in the Northwest Atlantic. AtlantNIRO Collected Scientific Papers: Oceanographic basis of formation of biological production in the North Atlantic, p.212- 234 (in Russian)

Kudlo B.P., V.A. Borovkov and N.G. Sapronetskaya. 1984. Results from Soviet oceanographic studies under the Flemish Cap project in 1977-1982. PINRO Collected Scientific Papers : Issues of fisheries oceanography of the Northern basin, p.86-98 (in Russian)

Vaskov, A.A. MS 2002. Assessment of Redfish Stock on the Flemish Cap Based on Data from the Russian Trawl Survey in 2001. NAFO SCR Doc. 02/9 Ser. No N4610, 16 p.

Vazquez A. and L. Motos. MS 1999. An Assessment of the Cod Stock in NAFO Division 3M. NAFO. SCR Doc. 99/56, Serial No. N4115, 26 p.

Zubov N.N. and O.I. Mamaev. 1956. Dynamic method for computing the elements of sea currents. Gidrometizdat Publishers, Leningrad, 115 p. (in Russian) 